\author{
International Journal of Innovative Research in \\ Electrical, Electronics, Instrumentation and Control Engineering
}

Vol. 9, Issue 10, October 2021

DOI: $10.17148 /$ IJIREEICE.2021.91010

\title{
Liquid butadiene rubber as safe process-aid in natural rubber product : A substitute for carcinogenic aromatic oils
}

\author{
Chandresh Mysore Parameshwaraiah ${ }^{1}$, Roopa $S^{2}$, Bhavana $\mathbf{M}^{3}$ \\ ${ }^{1}$ Assistant Professor - Department of Polymer Science \& Technology (PST), Sri Jayachamarajendra College of \\ Engineering (SJCE), JSS Science and Technology University (JSSSTU), Mysuru, Karnataka \\ ${ }^{2}$ Associate Professor - PST, SJCE, JSSSTU, Mysuru, Karnataka \\ ${ }^{3}$ UG - PST, SJCE, JSSSTU, Mysuru, Karnataka
}

\begin{abstract}
In rubber product formulation, the processing oils are important ingredients that eases mixing, filler dispersion, shaping and finetuning of mechanical properties. Aromatic oils are one of the widely used process aids since 1950 s, but of late it has acquired legal constraints since 2010 which is based on the report by Swedish National Chemicals Inspectorate. Aromatic oils have been criticized and restricted by European countries owing to the presence of poly cyclic aromatic hydrocarbons (PAHs) beyond the permissible limits. PAHs are regarded as volatile organic compounds, persistent toxic substances, persistent organic pollutants for their negative ecological impact due to their high volatility, reactivity, teratogenicity, mutagenic and carcinogenic power. They enter into food chain through air, water, soil and organisms. Thus, as the need of the hour, present work outlays an alternate safe substance 'liquid butadiene rubber' (LBR) as a non-carcinogenic process aid. It is non-aromatic and can be synthesized from various sources. The LBR [1, 2, 4, 6 and 8 parts per hundred rubber (phr)] is used in the formulation and have been studied for its effect on Mooney viscosity, curing characteristics and mechanical properties. From the characterization and test data, LBR was found to be a promising substitute as it offered the results equivalent to that of the control compound containing 10phr of conventional aromatic oil. This effort could give way to shift our dependency from non-renewable crude oil to other synthetic / natural renewable sources resulting in ecological sustainability.
\end{abstract}

Keywords: Liquid butadiene rubber (LBR), safe plasticizer, carcinogenic aromatic oil, natural rubber (NR)

\section{INTRODUCTION}

Plasticizers (i.e. process aids/ lubricating oils) are one of the important ingredients used in the rubber product formulations. They being liquids / viscous substances are majorly used to- reduce the rubber compound's viscosity, enhance product flexibility, lower the energy consumption for mixing / dispersing the ingredients and facilitate shaping of elastomer. Among the process aids, the aromatic oils predominate in elastomer industries, since 1950s, as they are compatible and economical (for the reason that they are non-polar organic substances and are derived from petroleumsources respectively). On an important note, use of aromatic oil has a negative impact on environment due to presence of polycyclic aromatic hydrocarbons (PAHs) in it, and of late it has acquired legal constraints since 2010 which is based on the report by Swedish National Chemicals Inspectorate. They have been criticized and restricted by European countries owing to the presence of poly cyclic aromatic hydrocarbons (PAHs) in beyond the permissible limits. PAHs are regarded as volatile organic compounds, persistent toxic substances and organic pollutants for their negative ecological impact due to their high volatility, reactivity, teratogenicity, mutagenic and carcinogenic power. They enter into food chain through air, water, soil and organisms. Hence, they are regarded as eco-detrimental [1]. On the other hand, depletion of non-renewable resources and increasing global warming are also the reasons to explore alternatives to replace present conventional plasticizers [2].

Liquid rubbers being oligomers, can be considered as noteworthy alternatives to substitute petroleum based hazardous aromatic oils. Liquid butadiene rubber (LBR or LBR-307) could serve as an assuring alternative mainly for following reasons - i) its molecular weight that falls between the elastomers and conventional process oils; ii) the hydrocarbon back bone that makes it compatible with organic elastomers; and iii) the unsaturation that offers co-vulcanization with solid elastomers (viz. NR, SBR, BR, EPDM), thus serving as a non-aromatic safe reactive plasticizer. This consideration was evolved from some of the investigations carried out using liquid rubbers.

In recent years of study, Sando et al. explored the plasticizing effect of hydroxyl-terminated liquid butadiene rubber as a reactive plasticiser in 1 - chlorobutadiene- butadiene rubber (CB-BR). The blend exhibited good plasticity with decrease 


\section{IJIREEICE}

\section{International Journal of Innovative Research in \\ Electrical, Electronics, Instrumentation and Control Engineering}

Vol. 9, Issue 10, October 2021

\section{DOI: 10.17148/IJIREEICE.2021.91010}

in Mooney viscosity [3]. Nakazano et al. reported the effect of liquid butadiene rubber (LBR) as plasticizer on styrenebutadiene copolymer vulcanizates, investigating its effect on phase separation, mechanical properties and thermal ageing where it was revealed that LBR had very less changes in the measurement values of mechanical properties both before and during ageing [4] [5]. Even the liquid isoprene rubber has been explored as reactive plasticizer in NR compound [6]. However, it was noted that, 'the effect of liquid butadiene rubber (LBR-307) as a reactive plasticiser with natural rubber (NR) compound as a replacement to aromatic oil' is yet not reported systematically such that its replacement is justified in terms of the properties that it offers with regard to viscosity, curing and tensile strength on par with the existing aromatic oil. Thus, in the present study, authors have prepared a series of NR compounds with LBR as safe process aid and have investigated on its effect on Mooney viscosity, curing characteristics, hardness and tensile properties which are the important fundamental characteristics that readily get effected by reactive plasticizer. The results were compared with control compound (CTR) containing conventional aromatic oil as plasticizer.

\section{EXPERIMENTAL}

\subsection{Materials}

The materials used in the present investigation for developing NR based tire compound formulation (Table 1) includesLiquid butadiene rubber (LBR-307, $\left\langle\mathrm{M}_{\mathrm{n}}>8000 \mathrm{~g} / \mathrm{mole}\right.$, Specific gravity $0.89, \mathrm{~T}_{\mathrm{g}}-95^{0} \mathrm{C}$ and viscosity $0.03 \mathrm{~Pa} . \mathrm{s}$ ) which was procured from Kuraray Industries, Japan; followed by Sheet natural rubber (NR) RMA\#4 from MARDEC International, Kaula Lumpur, Malaysia. Other rubber ingredients such as Renacit (2,2'-dibenzamidodiphenyldisulphide), zinc oxide, stearic acid, coumarone indene (CI) resin, micro crystalline (MC) wax, 2, 2, 4-trimethyl-1, 2-dihydroquinoline (TDQ), para phenylenediamine (6 PPD), high abrasion furnace carbon black (N330 or HAF c-black), aromatic oil, sulphur (soluble), N- tert-butyl-benzothiazole sulphenamide (TBBS) and N- 5 (cyclohexyl thio)-phthalimide (pre vulcanisation inhibitor, PVI), which were of commercial grades obtained from local suppliers.

\subsection{Methods and equipment}

\subsubsection{Compound preparation}

The compounding ingredients were mixed using a two-roll mill (6"x13", Sohal Engg. Works, Mumbai) at room temperature in accordance with ASTM D3184 (standard practices for rubber - evaluation). In the present work, the LBR content was varied from 1-8 phr and for the purpose of comparing the effect of LBR content on the properties, the control compound containing $10 \mathrm{phr}$ of aromatic oil was also prepared. The formulations used in this work is tabulated in Table 1 .

Table 1: Rubber Compound Formulation

\begin{tabular}{|l|l|l|l|l|l|l|}
\hline Ingredients ${ }^{\text {\#a }}$ (in phr) & CTR & LBR 1 & LBR 2 & LBR 4 & LBR 6 & LBR 8 \\
\hline Natural rubber & 100 & 100 & 100 & 100 & 100 & 100 \\
\hline Liquid butadiene rubber & 0 & 1 & 2 & 4 & 6 & 8 \\
\hline Aromatic oil & 10 & 0 & 0 & 0 & 0 & 0 \\
\hline
\end{tabular}

\#a Other compounding ingredients added to the above formulations were kept constant in the quantity as mentioned ahead: Renacit - 0.7, zinc oxide - 4.5, stearic acid - 2.5, CI resin - 1.25, MC wax - 1, TDQ - 2, 6 PPD - 1, HAF black - 63, sulphur - 2.1, TBBS - 1.8 and PVI - 0.35;

\subsubsection{Viscosity, curing characteristics and mechanical properties}

The Mooney viscosity (ML1+4 @ $100{ }^{\circ} \mathrm{C}$ ) of compound was determined using a Mooney viscometer (MV2000, Alphatech, USA) in accordance with ASTM D 1646. The green compounds' curing time was analysed using an oscillating disc rheometer (ODR, Techpro, USA) at $160^{\circ} \mathrm{C}$ as per ASTM D2084-01. The standard test specimens were moulded at $160{ }^{\circ} \mathrm{C}, 500$ psi using an electrically heated hydraulic compression moulding press (Modern Eng. Work, Mumbai) and the hardness (ASTM D 2240) followed by tensile properties (ASTM D412) were measured.

\section{RESULTS AND DISCUSSIONS}

\subsection{Mooney viscosity}

Mooney viscosity is one of the key characteristic properties of the rubber compounds, which gives an idea about the compound's processability. It can be observed from Figure 1 that the Mooney viscosity of test compounds decreased with increase in LBR content. Also, the values of LBR4 and LBR6 were found to be in close proximity with that of the control compound (CTR). This decrease in Mooney viscosity with addition of LBR symbolizes its softening nature, which ensures good flow characteristics during processing of NR compound [3]. 


\section{International Journal of Innovative Research in \\ Electrical, Electronics, Instrumentation and Control Engineering}

Vol. 9, Issue 10, October 2021

DOI: 10.17148/IJIREEICE.2021.91010

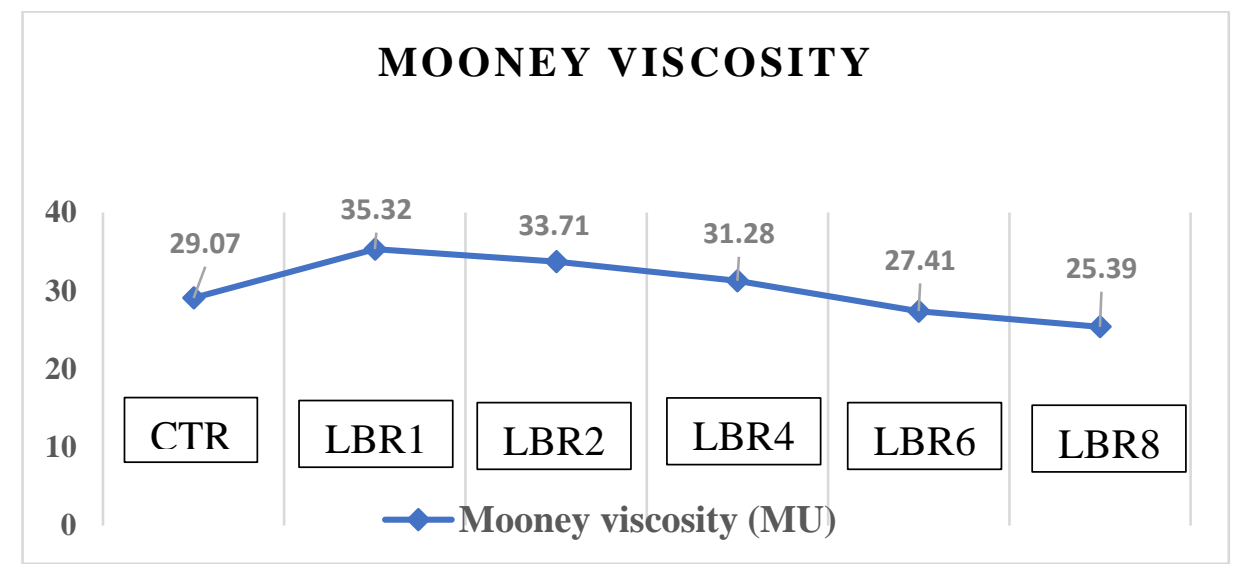

Figure 1: Effect of LBR on Mooney viscosity of NR Compound

\subsection{Cure characteristics}

Rheometer helps to analyse the cure characteristics of rubber compound and to monitor the processing characteristics as well. The results obtained from the rheography viz; $90 \%$ curing $\left(\mathrm{T}_{90}\right)$, the maximum torque $\left(\mathrm{M}_{\mathrm{H}}\right)$, minimum torque $\left(\mathrm{M}_{\mathrm{L}}\right)$ and the scorch time $\left(\mathrm{T}_{\mathrm{S} 2}\right)$ of samples are represented in Table $2 . \mathrm{M}_{\mathrm{L}}$ is the lowest resistance exhibited by rubber compounds prior to its crosslinking stage, indicating chain entanglement of rubber and the ease of processability of the compound. $\mathrm{M}_{\mathrm{H}}$ is the maximum resistance experienced by the rheometer disc due to increased viscosity of rubber compound as a result of maximum crosslinking. $\Delta$ Torque is the difference between maximum and minimum torque which solely attributes to the chemical crosslinks in the vulcanizate. It is observed that the $\mathrm{M}_{\mathrm{L}}$ of all the batches containing LBR are in accordance with the control compound with very slight deviations, which means that LBR offers similar plasticization as that of aromatic oil. The $\mathrm{M}_{\mathrm{H}}$ values of LBR containing compounds lies in the range of $1.659-1.934 \mathrm{Nm}$, which are slightly higher than the control compound $(1.568 \mathrm{Nm})$. Also, the $\Delta$ Torque is slightly higher in LBR containing compounds than the control compound and this could be due to the crosslinking of LBR. M. Mazliah et.al. have also reported such increase in torque indicating the crosslinking of the liquid rubber. [7].

Table 2: Effect of LBR on Cure characteristics

\begin{tabular}{|c|c|c|c|c|c|}
\hline Sample & $\begin{array}{c}\mathrm{M}_{\mathrm{L}} \\
(\mathrm{Nm})\end{array}$ & $\begin{array}{c}\mathrm{M}_{\mathrm{H}} \\
(\mathrm{Nm})\end{array}$ & $\mathrm{Ts}_{2}$ (Min.) & $\mathrm{T}_{90}(\mathrm{Min})$. & $\begin{array}{c}\Delta \text { Torque } \\
(\mathrm{Nm})\end{array}$ \\
\hline CTR & 0.103 & 1.568 & 1.61 & 3.07 & 1.465 \\
\hline LBR1 & 0.141 & 1.722 & 1.45 & 2.94 & 1.581 \\
\hline LBR2 & 0.107 & 1.934 & 1.56 & 3.14 & 1.827 \\
\hline LBR4 & 0.113 & 1.837 & 1.44 & 2.97 & 1.724 \\
\hline LBR6 & 0.116 & 1.772 & 1.53 & 3.08 & 1.656 \\
\hline LBR8 & 0.119 & 1.659 & 1.40 & 3.02 & 1.540 \\
\hline
\end{tabular}

Table 3: Effect of LBR on hardness and tensile properties

\begin{tabular}{|c|c|c|c|c|}
\hline Sample & $\begin{array}{c}\text { Hardness } \\
\text { (shore A) }\end{array}$ & $\begin{array}{c}\text { Modulus @ 300\% } \\
\text { elongation }(\mathrm{MPa})\end{array}$ & $\begin{array}{c}\text { Tensile strength } \\
(\mathrm{MPa})\end{array}$ & $\begin{array}{c}\text { Elongation at } \\
\text { break }(\%)\end{array}$ \\
\hline CTR & 65 & 12.9 & 18.4 & 413 \\
\hline LBR1 & 72 & 18.1 & 23.5 & 318 \\
\hline LBR2 & 70 & 17.5 & 22.8 & 323 \\
\hline LBR4 & 69 & 17.2 & 22.3 & 365 \\
\hline LBR6 & 67 & 15.1 & 21.5 & 402 \\
\hline LBR8 & 65 & 13.9 & 19.1 & 410 \\
\hline
\end{tabular}




\section{International Journal of Innovative Research in \\ Electrical, Electronics, Instrumentation and Control Engineering}

Vol. 9, Issue 10, October 2021

\section{DOI: 10.17148/IJIREEICE.2021.91010}

Shore-A hardness and tensile properties of all the NR vulcanizates were measured as per ASTM standards. The results obtained are summarized in Table 3. It is known that the mechanical properties of vulcanizates are dependent on the crosslink density of the compound and the net effect of plasticizer, reinforcing filler. In the present case, the filler content is kept constant and the process variables (like time, temperature and pressure involved in mixing, shaping and vulcanization) were all maintained same for all the compounds. Hence, the only parameter that would influence the compound's property could be attributed to process aid. From the test results, it was found that, compared to CTR, the compounds containing LBR show slightly higher hardness, tensile strength and modulus (@300\% elongation); and lower elongation at break. However, with increase in LBR concentration, its plasticization effect becomes significant and consequently the LBR8 offers tensile properties equivalent to CTR.

\section{CONCLUSION}

An attempt made to replace the aromatic oil (carcinogenic plasticizer) in rubber vulcanizates by liquid butadiene rubber (LBR-307) is a potential work as the fundamental properties of NR compound (viz. Mooney viscosity, curing characteristics, hardness and tensile properties) offered by the incorporation of LBR (between 6 and 8 phr) was equivalent with that of the control compound having $10 \mathrm{phr}$ of aromatic oil.

\section{REFERENCES}

1. Mohapatra S. and Nando G. B. "Cardanol: a green substitute for aromatic oil as a plasticizer in natural rubber". Rsc Advances, 4(30), pp.15406$15418,2014$.

2. Indrajati I. N. and Dewi I. R. "Performance of maleated castor oil based plasticizer on rubber: rheology and curing characteristic studies". In IOP Conference Series: Materials Science and Engineering (Vol. 223, No. 1, p. 012001). IOP Publishing, 2017.

3. Sando K, Kohjiya S, Ikeda Y, Yamashita S. and Kawabata N. "Liquid rubber as a reactive softener for 1-chlorobutadiene-butadiene rubber". Journal of applied polymer science, 62(7), pp.1093-1098, 1996.

4. Nakazono T. and Matsumoto A. "Mechanical properties and thermal aging behavior of styrene-butadiene rubbers vulcanized using liquid diene polymers as the plasticizer". Journal of applied polymer science, 118(4), pp.2314-2320, 2010.

5. Nakazono T., Ozaki A. and Matsumoto A. "Phase separation and thermal aging behavior of styrene-butadiene rubber vulcanizates using liquid polymers as plasticizers studied by differential scanning calorimetry and dynamic mechanical spectroscopy". Journal of Applied Polymer Science, 120(1), pp.434-440, 2011.

6. Chandresh M. P., S. Roopa and Siddaramaiah. "Liquid isoprene rubber as a safe processing aid in natural rubber compounds". Rubber Science, 34(1), 91-100, 2021.

7. Mazliah, M., Mohamad, N., Jeefferie, A.R. and Effendy, A.H., "Cure characteristics and tensile properties of natural rubber vulcanizates modified by tapioca starch”. Proceeding of Mechanical Engineering Research Day, pp.163-4, 2016. 